\title{
Los Museos Locales de Córdoba, un Fenómeno Singular
}

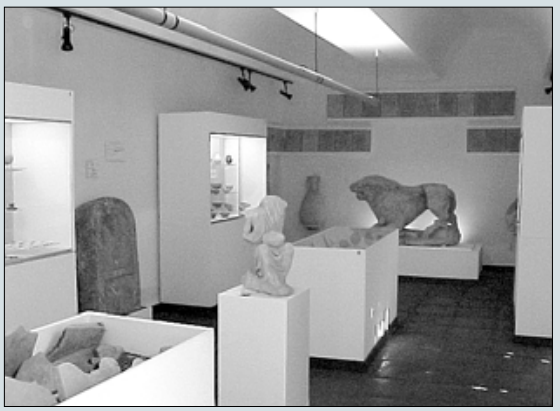

En las dos últimas décadas Córdoba ha asistido a un hecho realmente excepcional en el ámbito de la cultura y el patrimonio histórico: la espectacular proliferación a lo largo y ancho de su geografía de numerosos museos locales. Con ello nos encontramos ante un fenómeno casi sin parangón en suelo español y único en Andalucía, como lo confirman las propias cifras: hasta el momento existen 22 museos locales en Córdoba (actualmente hay en proyecto algunos más), lo que, sobre un total de 72 municipios que componen la provincia, supone que casi un tercio de los pueblos cordobeses cuentan actualmente con un museo. El hecho parece cobrar aún más importancia si tenemos en cuenta que más del $50 \%$ de la población cordobesa se encuentra bajo el radio de acción de dichos museos, al constituir los municipios en los que existe este tipo de instituciones de los más poblados de la provincia.

La causa del surgimiento de estos museos hay que buscarla en la conjunción de una serie de factores que se remontan a los momentos de la transición y primeros años de democracia en España, tales como el aumento de conciencia sobre el valor cultural y social del Patrimonio Histórico, la transferencia de competencias en materia cultural desde el Estado Central a las Comunidades Autónomas, la labor que en pro de estas instituciones museísticas hicieron una serie de personas que $\sin$ miedo se pueden considerar aventajados a su tiempo (especialmente la figura de Juan Bernier) y, por último, la gran potencialidad arqueológica del suelo cordobés, que ha hecho aflorar numerosos restos, con ocasión de las labores agrícolas, suscep- tibles de formar parte de colecciones públicas municipales.

Actualmente, los museos locales de Córdoba, en su mayoría de carácter predominantemente arqueológico, se ocupan de tareas de recuperación, conservación, investigación y difusión del patrimonio, lo que los convierte en órganos no sólo apropiados, sino también imprescindibles para complementar a las instituciones implicadas en la gestión del patrimonio, constituyendo el último peldaño administrativo -el municipio- en que debe recaer la responsabilidad de dicha gestión. Pero su funcionamiento varía mucho de unos museos a otros, dependiendo generalmente del poder económico del municipio en que to, lo que dificulta enormemente su buen funcionamiento. No es casualidad que los pocos museos locales cordobeses dotados de personal sean los que mejor funcionen. En los demás casos, se trata de museos atendidos por personas con trabajos ajenos a la museología, por lo que su relación con el museo es, nunca mejor dicho, "por amor al arte", lo cual indefectiblemente se ve reflejado en el funcionamiento museístico.

Como contrapartida a estos problemas, debemos destacar un importante $y$, en nuestra opinión, ejemplar hecho: la creación, en 1994, de la Asociación Provincial de Museos Locales de Córdoba (APMLC), gracias a la cual los museos locales cordobeses han ad-

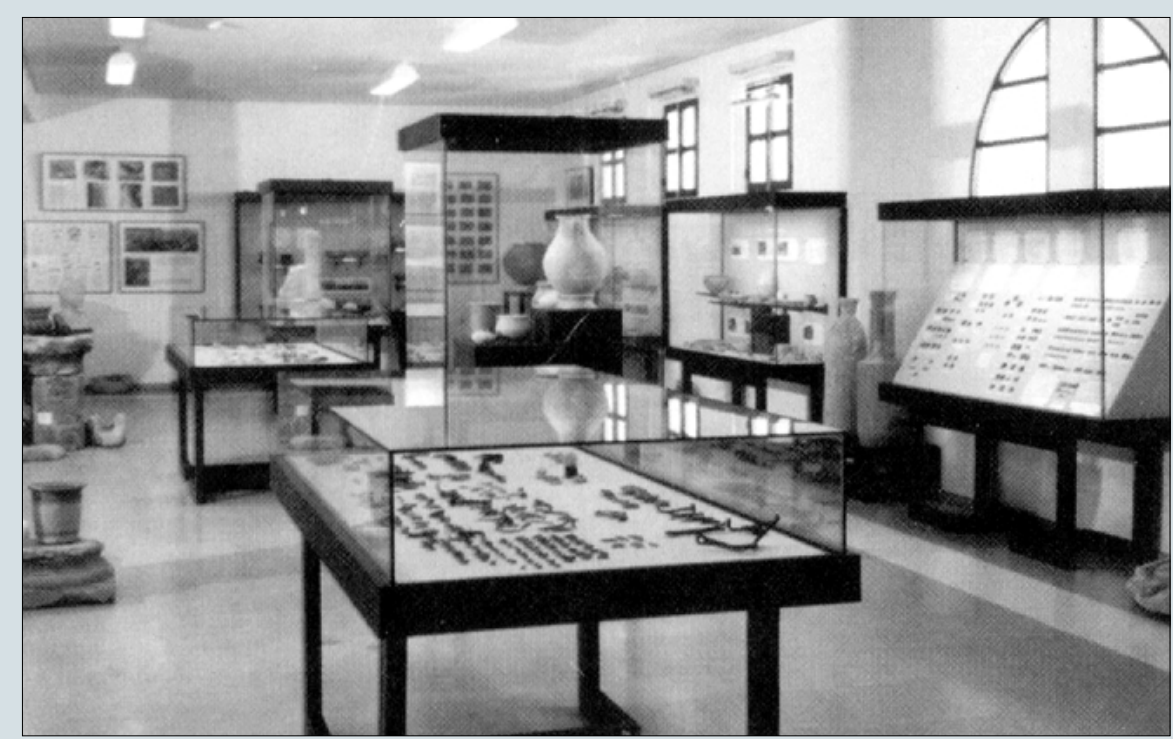

se enclavan (a más presupuesto mejor funcionamiento). Subvenciones anuales de la Consejería de Cultura de la Junta de Andalucía y de la Diputación Provincial de Córdoba contribuyen a paliar, sólo en parte, las deficiencias que presentan los museos en peor situación. Pero el principal problema que amenaza a estas instituciones culturales cordobesas es, sin duda, la escasez y desigualdad de recursos humanos con que cuentan. Se puede decir que, prácticamente en su totalidad, los museos carecen de personal laboral a ellos adscri- quirido cohesión y calidad en sus funciones y se han proyectado más vívidamente a la sociedad cordobesa, definiendo más claramente su rol y sus funciones sociales. Dicha asociación surgió con el ánimo de unir fuerzas, dado que unos museos se enclavaban en pueblos grandes y otros en municipios más pequeños, hallándose éstos en situaciones francamente peores y más desfavorables. En sus reuniones se tratan asuntos y problemas comunes o particulares de todos los museos cordobeses y desde ella se han 
acometido importantes acciones patrimoniales, como la colaboración con el SE.PRO.NA de la Guardia Civil en orden a controlar mejor las infracciones y delitos contra el patrimonio, la organización de una serie de cursos internos para dotar de una formación mínima en conservación a los responsables de los museos, la edición de un boletín periódico, una guía y una página Web que recogen aspectos de interés sobre cada uno de los museos y las poblaciones donde se enclavan o, finalmente, la firma de un convenio de colaboración entre la Asociación y la Universidad de Córdoba, colaboración que se concreta en cuatro puntos principales: potenciar y completar la capacitación de los universitarios cordobeses para el ejercicio de su actividad profesional, fomentar el conocimiento de los museos locales de la provincia de Córdoba, extender la cultura universitaria, y, por último, desarrollar proyectos conjuntos de investigación. Es evidente, pues, que sin esta asociación el funcionamiento de los museos locales de
Córdoba distaría mucho de ser tal y como hoy es. Todo ello hace tanto de APMLC como de los propios museos que representa instituciones realmente singulares y modélicas en el panorama cultural de Córdoba y Andalucía, a pesar de que aún quedan muchos problemas y necesidades que cubrir; esperemos que se vean solucionados, al menos en parte, en los próximos años.

Antonio Martínez Castro Asociación Provincial Museos Locales de Córdoba

\section{Jornadas Hispánicas de Historia del Vidrio}

Durante los pasados 30 de junio y I y 2 de julio tuvieron lugar en Sitges las I Jornadas Hispánicas de Historia del Vidrio, organizadas por la Fundació Centre del Vidre de Barcelona. Durante las sesiones de trabajo, los artistas y especialistas pudieron intercambiar experiencias e informaciones sobre los avances de sus investigaciones, el estado de las colecciones que gestionan y la situación de nuestro patrimonio en vidrio, en concreto en los siguientes ámbitos:

$\begin{array}{lr}\text { Vidrio antiguo } & \text { Vidriera antigua } \\ \text { Vidrio medieval } & \text { Vidriera contemporánea } \\ \text { Vidrio moderno } & \text { Museos y Colecciones } \\ \text { Vidrio contemporáneo } & \text { Restauración }\end{array}$

Esta disciplina vive en España una peculiar situación, al existir un importante grupo de arqueólogos, historiadores o críticos que le dedican sus esfuerzos, con la creación de un corpus relativamente importante de publicaciones. Así mismo el volumen de intervenciones sobre el patrimonio en vidrieras es significativo y la plástica contemporánea española comienza tímidamente a aceptar el vidrio como vehículo de expresión. A pesar de este alentador panorama, continúa existiendo una total desconexión entre los especialistas nacionales, lo cual implica una imposibilidad de dibujar unas líneas de trabajo, investigación y difusión comunes. La calidad de nuestro patrimonio en vidrio y el nacimiento de una nueva generación de artistas que trabajan con este material como soporte expresivo, son los dos motores principales que nos hacen creer en la necesidad de construir un marco de encuentro de estas características.

En el aspecto histórico hemos de destacar un gran avance en nuestro país en la publicación de estudios parciales o globales que demuestran claramente un mayor interés por parte de la comunidad científica por el tema, al entender el destacado papel del vidrio en el desarrollo de nuestra cultura histórica y artística, desde la antigüedad hasta la época actual. Creemos que es obvio que existe un importante desequilibrio entre la calidad y el volumen de nuestro patrimonio en vidrio y la pobre repercusión de los estudios o proyectos para su conservación o difusión. Esta situación ha de cambiar, potenciando el aprecio colectivo del vidrio artístico y la toma de conciencia de las autoridades hacia una planificación responsable que asegure su protección.

Una parte significativa de nuestro patrimonio en vidrio se encuentra depositada en museos y colecciones públicas y privadas en el extranjero y a causa de una pobre difusión internacional de nuestros conocimientos actuales, es frecuente ver como vidrios españoles se presentan mal catalogados y normalmente asignados a orígenes y cronologías inciertas o simplemente desconocidas.

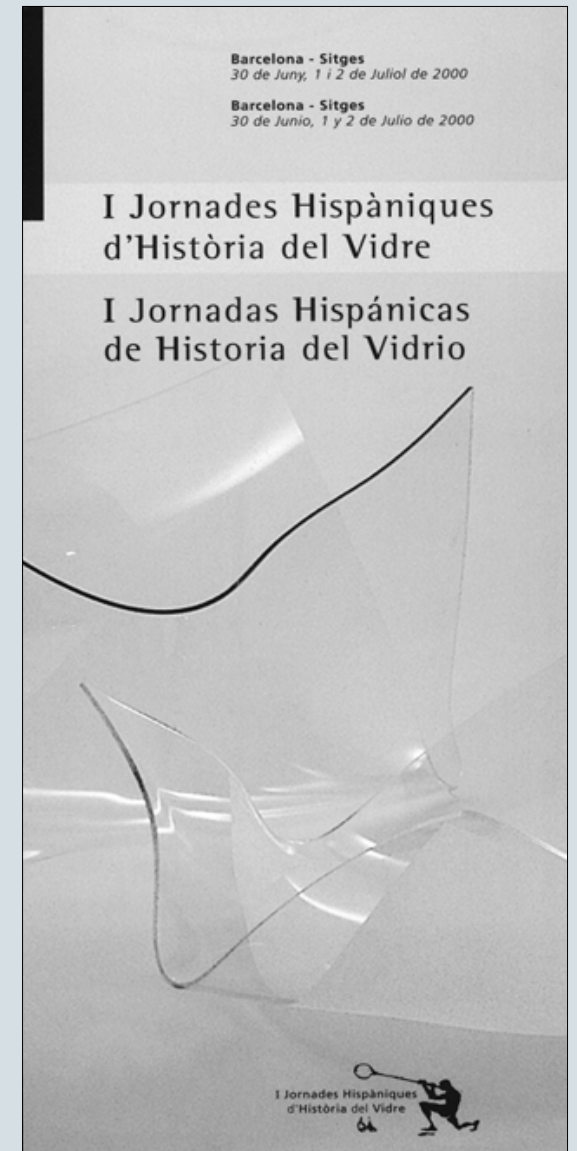

El resultado inmediato de las Jornadas será la publicación, el próximo mes de diciembre, de las Actas que fijarán en negro sobre blanco la literatura presentada en las sesiones de trabajo. Estas tendrán difusión nacional e internacional, ya que se enviarán a diferentes bibliotecas universitarias, especializadas y de museos de toda España y del resto del mundo. 